\title{
Handoff Study of Ring Shaped Cellular Configuration Designed for High Altitude Platform Communications
}

\author{
Mahmoud A. Elghorab \\ Department of Electronics and \\ Electrical Communications, \\ Faculty of Electronic \\ Engineering, Menoufia \\ University, \\ Menouf, Egypt, 32952
}

\author{
Ahmed S. Elkorany \\ Department of Electronics and \\ Electrical Communications, \\ Faculty of Electronic \\ Engineering, Menoufia \\ University, \\ Menouf, Egypt, 32952
}

\author{
Moawad I. Dessouky \\ Department of Electronics and \\ Electrical Communications, \\ Faculty of Electronic \\ Engineering, Menoufia \\ University, \\ Menouf, Egypt, 32952
}

\begin{abstract}
In this paper, the concentric ring shaped cellular configuration is designed for High Altitude Platforms (HAPs). An one dimensional (1D) vertical linear antenna array is used to generate this configuration. The effect of different types of HAP mobility models, e.g. drift, random walk, and reflection has been examined. The possibility of reducing the need for mechanical stabilization via handoff techniques is demonstrated through the study of handoff, dropping, and blocking probabilities.
\end{abstract}

\section{General Terms}

Handoff probability, blocking probability, and dropping probability.

\section{Keywords}

High Altitude Platforms (HAPs), concentric ring shaped cells, handoff probability, blocking probability, and dropping probability.

\section{INTRODUCTION}

HAPs are aircrafts or airships operating at an altitude in the range of $17-22 \mathrm{~km}$ in the stratosphere [1]. HAPs can find a place in the world of mobile communications. They have many advantages when compared to terrestrial systems or satellite systems [2]. HAPs do not need a large number of base stations as in terrestrial mobile communications. Also, they do not have problems like the limitations on the minimum cell size which appear in GEO satellite systems and handover problems provided by LEO satellites [1]. One of the major advantages of HAPs is the superior radio coverage in wireless communications because of the availability of line of sight communications as in satellite communications but with lower propagation losses due to the reduced altitude [1-5]. There are many other advantages of HAPs, e.g. easy deployment, low cost operation, flexibility, and broad coverage. HAPs can afford multiple broadband services, e.g. broadband internet access, video conferencing, voice telephony, voice over IP, entertainment services (radio and TV broadcasting and video on demand), distance learning, and telemedicine [1].

The instability of HAP position is the main disadvantage of HAPs. It requires frequent stabilization of the HAP antenna [6]. Another major problem is the rotation of the HAP around its central axis. This problem has a great effect on the outer cells in the hexagonal configuration [7]. It requires either redirecting all the beams forming the cells or performing high rate handoff techniques [6]. A solution of this problem is dividing the coverage area into concentric ring shaped cells [8]. This configuration affords many advantages, e.g. the reduction of the required motion monitoring and the needed corrections. Also, it reduces the power consumption.

In this paper, a 1D vertical linear antenna array is used to generate the concentric ring shaped cells to reduce both the antenna payload and the implementation complexity of the 2D array [6], [9-10].

Dividing the coverage area into concentric ring shaped cells solved the problem of HAP rotation around its central axis. For the other different types of HAP mobility models, handoff is expected to help users continue the calls with minimum dropping probability. Acceptable levels of blocking and dropping probabilities can reduce the need for mechanical stabilization.

The paper is arranged as follows, section 2 demonstrates High Altitude Platform mobility models. Section 3 illustrates the handoff simulation. Section 4 shows the Numerical results and, finally, conclusions are included in section 5 .

\section{MOBILITY MODELS FOR HIGH ALTITUDE PLATFORMS}

HAPs may experience different types of movements, the drift movements with respect to $\mathrm{x}, \mathrm{y}$, and $\mathrm{z}$-axis and the rotational movements with respect to $\mathrm{x}, \mathrm{y}$, and $\mathrm{z}$-axis known as pitch, roll, and yaw respectively. Only the effect of $x$ and z-axis drift and rotation was considered because the $\mathrm{x}$ and $\mathrm{y}$-axis drift and $\mathrm{x}$ and $\mathrm{y}$-axis rotation have the same effect on the performance of the system [6]. The drift and rotation movements can be combined into more complicated types of movements, e.g. reflection and random walk. The limitations on the boundaries of the HAP movement are specified according to ITU [11], where the HAP should be kept within a circle of radius $400 \mathrm{~m}$ and height limits of $700 \mathrm{~m}$. The HeliNet project positioned the platform within a cylinder with a height of $3 \mathrm{Km}$ and a radius of $4 \mathrm{Km}$ for $99.9 \%$ of the time and within a cylinder with a height of $1 \mathrm{Km}$ and a radius of $2.5 \mathrm{Km}$ for $99 \%$ of the time [12].

\subsection{Drift Movement}

The HAP will start moving from the center of the coverage area $(0,0,20) \mathrm{Km}$ to one end of the position cylinder and then back to the other end. The current position for a drifting HAP is given by the following equation [6]:

$u_{t}=u_{t-\Delta t}+v \cdot \Delta t \cdot \hat{a}$ 
The current position is $u_{t}$. The previous position is $u_{t-\Delta t}$. The HAP velocity is $\mathrm{v}$.

\subsection{Random Walk Movement}

Random walk is a combination of two different types of movements, drift and yaw. The current position for a random walk movement is given by the following equation [6]

$u_{t}=u_{t-\Delta t}+\Delta t\left[v_{h} \cos (\theta) \hat{x}+v_{h} \sin (\theta) \hat{y}+v_{v} \hat{z}\right]$

The horizontal velocity component $\left(\mathrm{v}_{\mathrm{h}}\right)$ defines the horizontal HAP position. The vertical velocity component $\left(v_{v}\right)$ defines the rate of decent and ascent. Figure 1 illustrates an example of random walk movement [6]. HAP should be kept within cylindrical boundaries defined in HeliNet [12].

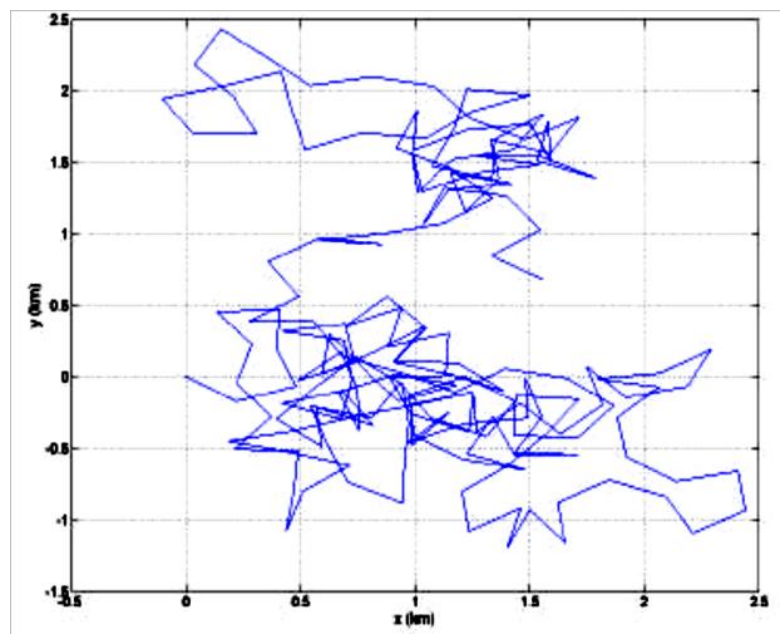

Fig 1: Random walk movement [6].

\subsection{Reflection Movement}

HAP moves to a point that is randomly located within the position cylinder. The current position of the HAP is given by the following equation [6]

$$
u_{t}=u_{t-\Delta t}+v \cdot \Delta t . \hat{a}
$$

The reflection and drift type movements have the same equation but the direction of the new location differs. For the reflection movement, the direction is randomly selected. For the drift movement, the direction is kept on a specific axis.

Figure 2 gives an example of reflection movement [6]. The HAP is kept within cylindrical boundaries defined in HeliNet [12].

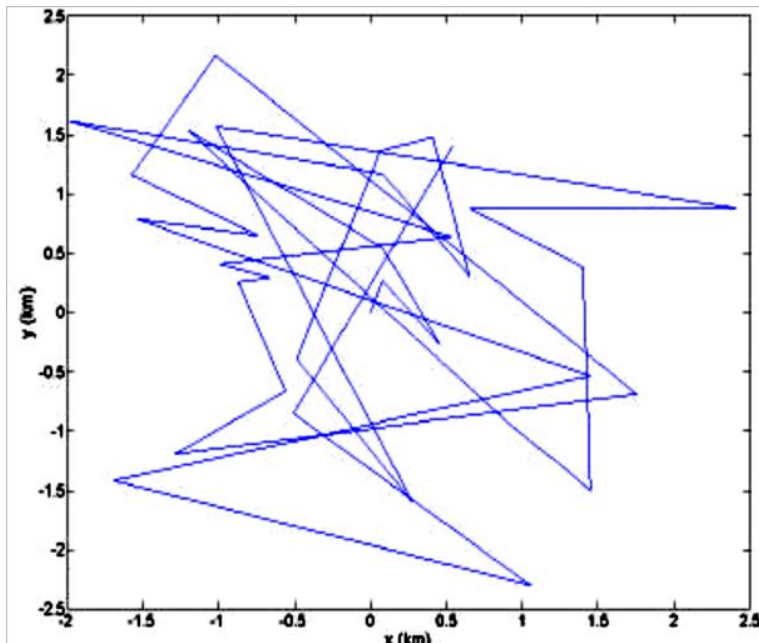

Fig 2: Reflection movement [6].

\section{HANDOFF SIMULATION}

The effect of HAP movement on station keeping represents a problem for HAP communications. A study of handoff as a potential solution for this problem is considered here.

Users are randomly distributed in a coverage area of radius $32.7 \mathrm{Km}$ divided into 23 concentric ring shaped cells generated by a vertical linear array antenna on the platform [6]. Line of sight communications have been proposed. The simulation parameters were introduced in the following table [6]. The radius of the coverage area, the noise level, the selected frequency, the platform altitude, the transmitted power, mean call holding time, and HAP speed parameters are identical to the reference values. The other parameters, e.g. the number of cells, the number of channels per cell, the cluster size, and the offered traffic are changed according to the proposed communication scenario of the concentric ring shaped cells.

Table 1. Handoff simulation parameters

\begin{tabular}{|c|c|}
\hline parameters & values \\
\hline Noise received level & $-133.9 \mathrm{dBm}$ \\
\hline Frequency & $30 \mathrm{GHz}$ \\
\hline Platform altitude & $20 \mathrm{Km}$ \\
\hline Transmitter power & $-26.6 \mathrm{dBm}$ \\
\hline Number of cells & 23 \\
\hline Channels per cell & 400 \\
\hline Total offered traffic & 641.67 \\
\hline Cluster size & 2 \\
\hline HAP initial position & $(0,0,20) \mathrm{Km}$ \\
\hline $\begin{array}{c}\text { Mean arrival rate for } \\
\text { each user }\end{array}$ & $10 \mathrm{calls} / \mathrm{hour}$ \\
\hline Mean call holding time & $300 \mathrm{sec}$ \\
\hline HAP speed & $0-200 \mathrm{Km} / \mathrm{h}$ \\
\hline
\end{tabular}


The Poisson process governs call generation. The holding time of each call changes according to the exponential distribution. The traffic is uniformly randomly distributed [6].

\section{NUMERICAL RESULTS}

Results of handoff, blocking, and dropping probabilities for the previous three different movement models of HAP movement are introduced as follows:

For the $\mathrm{x}$-axis drift movement, figure 3 illustrates the increase of handoff probability with the increase of HAP velocity. The rate of increase for speeds below $100 \mathrm{Km} / \mathrm{h}$ is larger than for higher speeds. The handoff probability is approximately constant for speeds between 100 and $120 \mathrm{Km} / \mathrm{h}$. It increases again to reach a maximum handoff probability of $82.1 \%$ at $160 \mathrm{Km} / \mathrm{h}$ then it decreases at speeds from $160-180 \mathrm{Km} / \mathrm{h}$. It is approximately constant again at speeds from $180-200 \mathrm{Km} / \mathrm{h}$ .The dropping probability due to the lack of channel availability is considered here, the simulation results show that the uniform random distributed users in a coverage area divided into concentric ring shaped cells experience no dropping probability for all the speeds of the HAP. Increasing the traffic raises the blocking probability above $2 \%$ and increases the dropping probability.

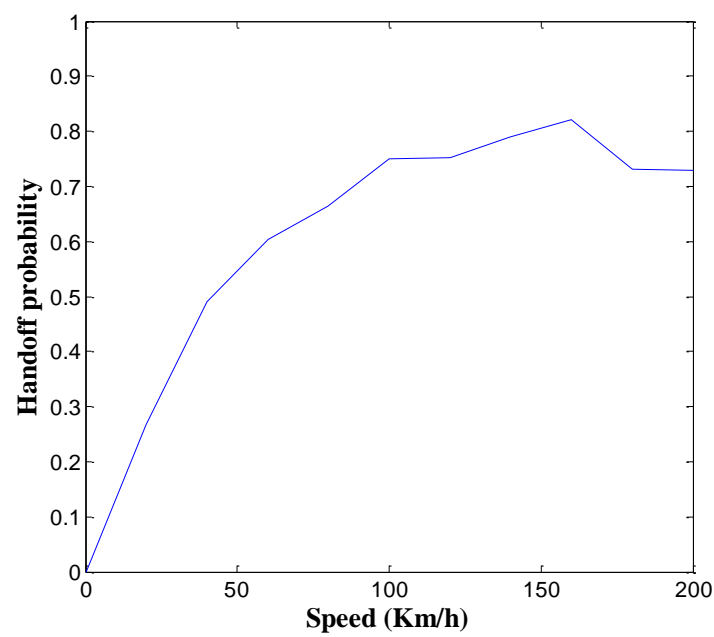

Fig 3: Handoff probability for drift movement

Figure 4 illustrates the change of blocking probability with HAP speed. The blocking probability decreases as the speed decreases with a maximum blocking probability of about $2 \%$ at $0 \mathrm{Km} / \mathrm{h}$. The chance for new calls to find free channels increases with the increase of HAP speed. The maximum rate of decrease is for a range of HAP speeds $(0-20 \mathrm{Km} / \mathrm{h})$. The rate of decrease of blocking probability decreases at speeds from $20-60 \mathrm{Km} / \mathrm{h}$ then it increases to reach the minimum blocking probability of $0.17 \%$ at $80 \mathrm{Km} / \mathrm{h}$. The blocking probability increases again at HAP speeds $80-140 \mathrm{Km} / \mathrm{h}$. It decreases for HAP speeds $140-180 \mathrm{Km} / \mathrm{h}$ then it increases again to reach $0.35 \%$ at $200 \mathrm{Km} / \mathrm{h}$.

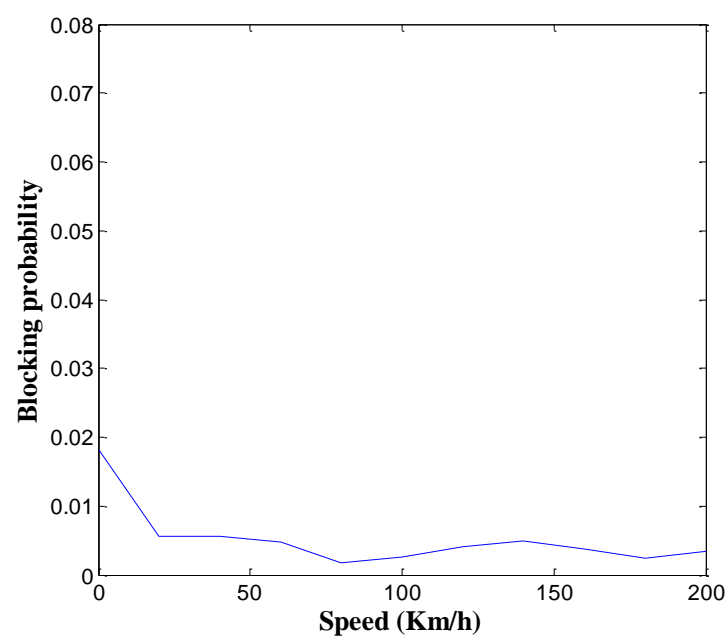

Fig 4: Blocking probability for drift movement

For the reflection type of movement, figure 5 illustrates the increase of handoff probability with the increase of HAP speed. The maximum rate of increase is at speeds from 40-60 $\mathrm{Km} / \mathrm{h}$. The maximum handoff probability is $91.2 \%$ at speed of $200 \mathrm{Km} / \mathrm{h}$. Also, the simulation results show no dropping probability for the reflection movement.

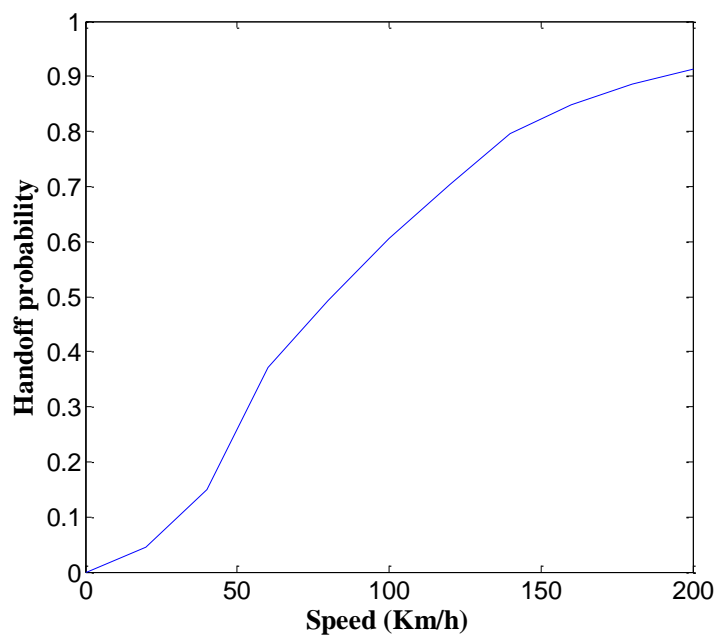

Fig 5: Handoff probability for reflection type of movement

Figure 6 illustrates the change of blocking probability with HAP speed. The blocking probability decreases as the speed decreases which means that the new incoming users experienced a better channel availability at higher speeds. A maximum blocking probability of approximately $2 \%$ is at 0 $\mathrm{Km} / \mathrm{h}$ then it decreases to reach $0.48 \%$ at $40 \mathrm{Km} / \mathrm{h}$. It decreases in a lower rate to reach $0.27 \%$ at $80 \mathrm{Km} / \mathrm{h}$ then it experiences a small increase to reach $0.37 \%$ at $100 \mathrm{Km} / \mathrm{h}$. The minimum blocking probability is $0.07 \%$ at $180 \mathrm{Km} / \mathrm{h}$. 


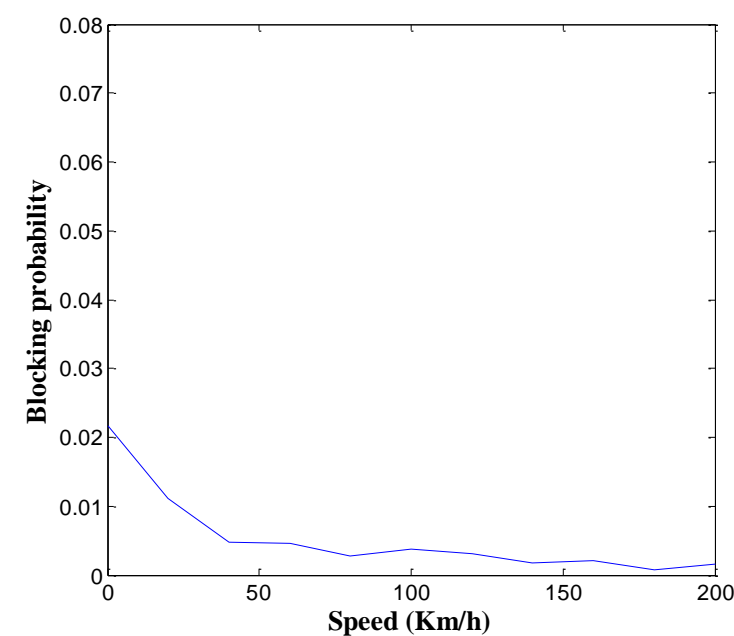

Fig 6: Blocking probability for reflection type of movement

For the random walk type movement, figure 7 illustrates the increase of handoff probability with the increase of HAP velocity. The handoff probability increases to reach $81.2 \%$ at $160 \mathrm{Km} / \mathrm{h}$ then it decreases to reach $79.3 \%$ at $180 \mathrm{Km} / \mathrm{h}$. It increases again to reach a maximum handoff probability of $86.7 \%$ at $200 \mathrm{Km} / \mathrm{h}$

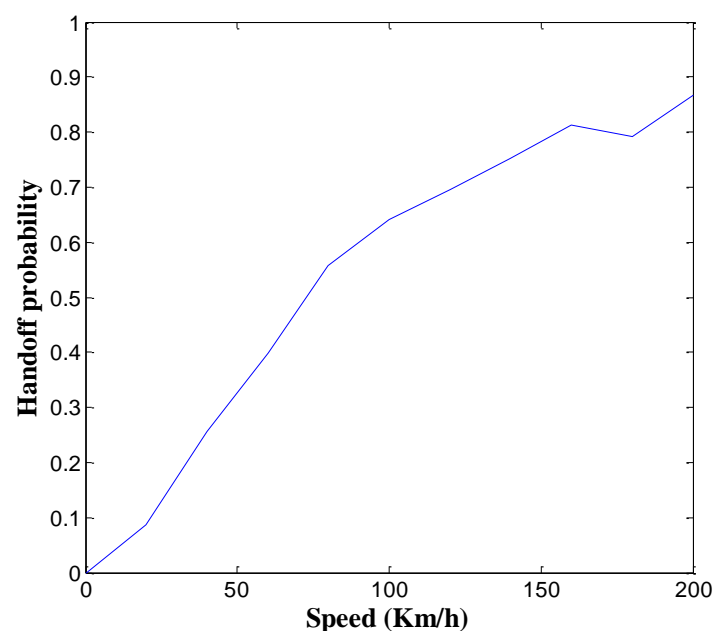

Fig 7: Handoff probability for the random walk type of movement

Figure 8 shows the change of the dropping probability with HAP speed. Users experience no dropping probability at speeds lower than $80 \mathrm{Km} / \mathrm{h}$. At higher speeds, the dropping probability starts to change to reach a maximum of $0.025 \%$ at $200 \mathrm{Km} / \mathrm{h}$.

Figure 9 represents the blocking probability. The maximum blocking probability of approximately $2 \%(1.67 \%)$ is measured at a HAP speed of $0 \mathrm{Km} / \mathrm{h}$. It decreases as the HAP speed increases to reach $1.12 \%$ at $20 \mathrm{Km} / \mathrm{h}$. For higher speeds, the blocking probability changes within a limited range. It increases again to reach $1.17 \%$ at $40 \mathrm{Km} / \mathrm{h}$ then it decreases to reach a minimum blocking probability of $0.76 \%$ at $100 \mathrm{Km} / \mathrm{h}$.

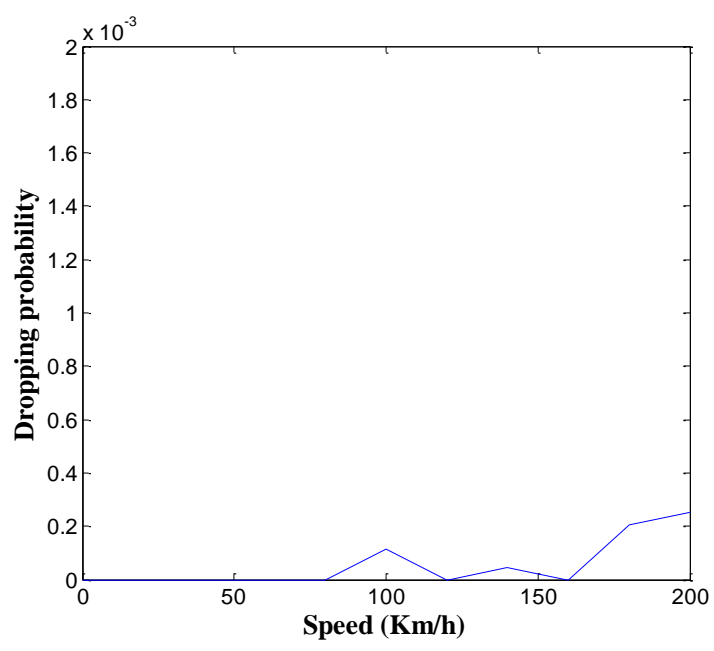

Fig 8: Dropping probability for random walk type of movement

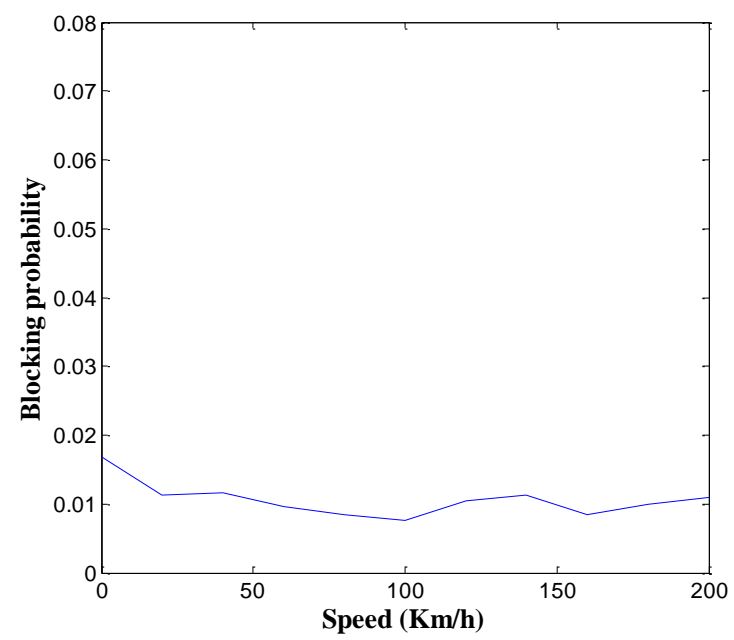

Fig 9: Blocking probability for random walk type of movement

\section{CONCLUSIONS}

The study of the effect of HAP movement in the concentric ring shaped cellular configuration shows the need for mechanical stabilization to overcome the problem of HAP movement. This stabilization can be reduced through the use of handoff techniques. For an acceptable blocking probability, approximately $2 \%$, the dropping probability is improved due to the proposed concentric ring shaped cellular configuration Three types of HAP motions were studied. The random walk has the worse effect because of the increase of the dropping probability.

\section{ACKNOWLEDGMENTS}

I would like to express appreciation to my supervisor Dr. Moawad I. Dessouky for his helpful supervision. Also, my gratitude to Dr. Ahmed S. Elkorany for his precious guidance and invaluable assistance. Last but not least, thanks to my family and my wife for their endless support and understanding.

\section{REFERENCES}

[1] www.comsoc.org/pubs/surveys. Broadband Communications via High-Altitude Platforms: A Survey. 
[2] Mingxiang, G., Fang, Y., and Qing, G. 2009. Performance of Coverage and Wireless Link for HAPS Communication. In Proceedings of the International Conference on Wireless Communications \& Signal Processing.

[3] Mohammed, A. and Yang, Z. 2009. Broadband Communications and Applications from High Altitude Platforms. International Journal of Recent Trends in Engineering. Vol 1, No. 3, May.

[4] Jun, W., Chu, Y. K., and Bin, T. 2010. Downlink Capacity of High Altitude Platforms CDMA Systems in Ricean Channel. In Proceedings of the 2nd International Conference on Computer and Automation Engineering

[5] Nofal, M. 2001. Bridging the information gap via stratospheric aeronautical platform communication system. 2001. Proceeding IEEE Inter. Conference on Mobile and Wireless Communications (MWCN'2001), Brazil, Aug., 14-17.

[6] www.capnina.com/D23a. Resource Allocation and Handoff Techniques for High Altitude Platforms. FP6IST-2003-506745 CAPANINA

[7] Elbagory, Y. 2014. Impact of High-Altitude Platforms rotation on cellular mobile communications. International Journal of Advanced Computing Research. Vol. 1, 8-13.
[8] Nofal, M., Hadhood, M., Dessouky, M., and Albagory, Y. 2002. A Novel Cellular Structure For Stratospheric Platform Mobile Communications. Nineteenth national radio science conference, Alexandria, March, 19-21.

[9] Albagry, Y., Dessouky, M., and Sharshar, H. 2007. Efficient Highways Coverage using High Altitude Platforms. Proceedings of Asia-Pacific Microwave Conference.

[10] Elghorab, M. A., Elkorany, A. S., and Dessouky, M. I. 2014. Concentric Ring Shaped Cellular Configuration for High Altitude Platforms using Particle Swarm Optimization. International Journal of Computer Applications. Vol. 96, No. 6, June, 23-26.

[11] ITU. 2000. Recommendation ITU-R F.1500, Referred characteristics of systems in the fixed service using high altitude platforms operating in the bands $47.2-47.5 \mathrm{GHz}$ and 47.9- 48.2 GHz. Vol. ITU-R S.672.

[12] D. Grace, J. Thornton, G. White, M. H. Capstick, T. C. Tozer, M. Mohorcic, U. Drcic, G. Kandus, T. Javornik, and E. Faletti. 2001. System Level Design Aspects for the Delivery of Broadband Services over Helinet. IST1999-11214 HeliNet project deliverable, HE-032-T1UNY-RP-01, 29th March. 